Łukasz Szternel ${ }^{1}$, Joanna Siódmiak ${ }^{1}$, Katarzyna Bergmann ${ }^{1}$, Karolina Perz ${ }^{1}$, Tadeusz Dereziński², Grażyna Sypniewska ${ }^{1}$

${ }^{1}$ Department of Laboratory Medicine, Nicolaus Copernicus University, Collegium Medicum in Bydgoszcz, Poland

2Outpatient Clinic "Esculap" in Gniewkowo, Poland

\title{
Comparison of two different methods for routine 25(OH)D measurement in paediatric serum samples
}

\section{Corresponding author:}

Łukasz Szternel MSc,

Department of Laboratory

Medicine, Collegium

Medicum NCU,

E:mail lukaszszternel@wp,pl
Medical Research Journal 2017; Volume 2, Number 4, 141-146 10.5603/MRJ.2017.0019

Copyright (C) 2017 Via Medica ISSN 2451-2591

\begin{abstract}
Over the last decade interest in automated assays for 25-hydroxy-vitamin D measurement have greatly increased. The presence of different metabolites of vitamin D in the blood influences measurement of its concentration. In paediatric subjects the basic interference is due to the presence of 3-epi-25(OH) $D_{2} / \mathrm{D}_{3}$, which despite their biological inactivity, influences the total concentration of 25(OH)D.

Aim: We assessed the analytical performance and usefulness of two different assays for measurement of total $25(\mathrm{OH}) \mathrm{D}$ in children.

Materials and Methods: The study was performed in blood samples taken from 100 school-children aged 9-11 years. In all serum samples 25(OH)D total concentration was measured with the use of chemiluminescent assay, which is known to show no cross-reactivity with 3-epi-25(OH)D, and with the use of a newly developed enzyme-immunosorbent method.

Results: The mean 25(OH)D concentration in children measured with enzyme-immunosorbent assay (EIA) was significantly higher, at $28.06 \mathrm{ng} / \mathrm{mL}$, than with the chemiluminescent assay (CLIA), at $21.13 \mathrm{ng} / \mathrm{mL}$; $<0.0001$. In children with optimal weight the average $25(\mathrm{OH}) \mathrm{D}$ was $32.93 \mathrm{ng} / \mathrm{ml}(\mathrm{EIA})$ and $21.5 \mathrm{ng} / \mathrm{mL}$ $(C L I A)(p<0.0001)$, respectively, whereas in a subgroup with overweight/obesity the mean concentration of $25(\mathrm{OH})$ D was similar, at $23.2 \mathrm{ng} / \mathrm{ml}(\mathrm{EIA})$ and $20.76 \mathrm{ng} / \mathrm{ml}(\mathrm{CLIA})(\mathrm{p}=0.15)$. The nonparametric Spearman's rank correlation of two methods equalled $0.47 ; 95 \% \mathrm{Cl}(0.11$ to 0.60$)$ with a significance leve $p<0.0001$. The calculated concordance correlation coefficient between two methods in the whole group was $0.26 ; 95 \% \mathrm{Cl}(0.17$ to 0.35$)$. In a subgroup of children with optimal body mass $(\mathrm{N}=50)$ the concordance correlation coefficient was $0.18 ; 95 \% \mathrm{Cl}(0.06$ to 0.29$)$, whereas in children with overweight/obesity $(\mathrm{N}=50)$ it was $0.44 ; 95 \% \mathrm{Cl}(0.29$ to 057$)$. Mean bias for the enzyme-immunosorbent method equalled $18.7 \% ;+/-1.96$ SD (101.3\% to $-64 \%)$

Conclusions: With reference to $25(\mathrm{OH}) \mathrm{D}$ measurement in children, Spearman's correlation coefficient indicated "moderate correlation" between the two compared methods, whereas the strength of agreement (concordance) between both methods was characterised as "poor". The proper selection of assay for accurate assessment of vitamin D status in paediatric samples is necessary to avoid misdiagnosis. Key words: Vitamin D, 25(OH)D concentration, CLIA, enzyme-immunosorbent method
\end{abstract}

Med Res J 2017; 2 (4): 141-146
Abbreviations: VDR-vitamin D receptor, VDBP-vitamin D binding protein, CLIA-immunochemiluminescence (method), HPLC- high-performance liquid chromatography, LC-MS/MS-liquid chromatography with tandem mass spectrometry, CCC-concordance correlation coefficient.

\section{Introduction}

The positive role of vitamin D on skeletal system has been known for years, but studies over the last decade have discovered another dimension of interaction between vitamin $\mathrm{D}$ and non-skeletal systems. The 
pleotropic effect of vitamin $D$ mediated by vitamin $D$ receptors localised on more than 60 types of cells affects more than 200 genes. The biological effects of interaction between vitamin D and VDR, besides calcium homeostasis, are inhibition of cell proliferation and promotion to maturation and regulation of the apoptosis [1-2].

Deficiency of vitamin $D$ is recognised regardless of gender, age, or race but some circumstances particularly contribute. Obesity, especially among children, constitutes one of these factors, which promotes insufficiency of vitamin D. Studies from different countries highlight the common problem of vitamin $D$ deficiency/insufficiency emerging among obese children [3-4]. An inverse correlation was found between fat mass and vitamin D status. Due to the increasing frequency of obesity and overweight among children and adolescents, the prevalence of parallel development of vitamin $D$ insufficiency seems to be a real threat for health [5]. Vitamin D deficiency and obesity emerging in childhood have been classified as epidemics. Both of them contribute to the development of serious diseases and also have common risk factors, which are inappropriate diet and lack of activity. To avoid developing impaired bone mineralisation and also to reduce the risk of developing diabetes type 1 and 2 or cardiovascular diseases, it is important to maintain optimal concentration of vitamin D [5].

Nowadays many laboratories routinely analyse the concentration of $25(\mathrm{OH}) \mathrm{D}$ in blood samples. Most assays allow measurement of total $25(\mathrm{OH}) \mathrm{D}$, including both forms: $25(\mathrm{OH}) \mathrm{D}_{2}$ and $25(\mathrm{OH}) \mathrm{D}_{3}$. This biomarker of vitamin $\mathrm{D}$ status is characterised by high stability under different storage conditions and also some pre-analytical impacts [6]. One should be aware that in some medical conditions, such as kidney failure, it is recommended to assess both metabolites: $25(\mathrm{OH}) \mathrm{D}$ and an active form $1,25(\mathrm{OH})_{2} \mathrm{D}$. Measurements of $25(\mathrm{OH}) \mathrm{D}$ are burdened with certain difficulties. The "matrix effect", related to interference with the serum components, is considered as one of the greatest analytical difficulties associated with the analysis of $25(\mathrm{OH}) \mathrm{D}$. It results from the specific structure of $25(\mathrm{OH}) \mathrm{D}$, which is characterised by high hydrophobicity [7]. Another kind of interference with measurement of $25(\mathrm{OH}) \mathrm{D}$ in the blood is the presence of different metabolites of vitamin $D$. There are more than 50 different metabolites of vitamin $D$, and some of them, such as 3-epi-25(OH) $D_{2} / D_{3}$, despite its biological inactivity, influence the total concentration of $25(\mathrm{OH}) \mathrm{D}$ [8-9]. A recent study reported that the concentration of 3-epi-25 $(\mathrm{OH}) \mathrm{D}_{3}$ is strictly related to the concentration of $25(\mathrm{OH}) \mathrm{D}_{3}$, and individuals with lower concentrations of total $25(\mathrm{OH}) \mathrm{D}_{3}$ consequently showed reduced levels of this metabolite [9]. Significantly elevated content of 3-epi-25(OH) $\mathrm{D}_{3}$ has been found in the paediatric population, especially in children below one year old [10]. The content of 3-epi-25(OH) $\mathrm{D}_{3}$ in infants can reach 9 to $61.1 \%$ of the total 25(OH)D [9]. The presence of different metabolites of vitamin $\mathrm{D}$ can contribute to misclassification between sufficiency and deficiency of vitamin $\mathrm{D}$ by inclusion of these metabolites into the total concentration of 25(OH)D [10].

Currently, a wide spectrum of different methods used for evaluation of vitamin D status is available. There are manual and automated immunoassays, methods of direct detection such as HPLC and LC-MS/MS, and recently a new developed enzyme-immunosorbent assay was adapted on general chemistry analysers [11]. Most commercially available automated immunoassays for 25(OH)D measurement use immunochemiluminescence technology. Identified differences between various assays basically result from the specificity of applied antibodies, which are characterised by lower or higher cross-reactivity with different metabolites of vitamin $\mathrm{D}[7,9]$.

Although most widely used commercially available immunoassays for analysis of 25(OH)D have comparable correlation coefficient values to the reference method LC-MS/MS, an overall significant bias was found when compared to LC-MS/MS, especially at lower concentrations of $25(\mathrm{OH}) \mathrm{D}(<30 \mathrm{ng} / \mathrm{mL})$ [12]. Most automated assays give reasonably accurate measurements, but certain pitfalls occur, which, in fact, are difficult to eliminate. The cross-reactivity with $24,25(\mathrm{OH})_{2}$ or 3 -epimers in some immunoassays can contribute to overestimation of $25(\mathrm{OH}) \mathrm{D}$ and consequently lead to misclassification of vitamin $D$ status. The percentage of 3-epi metabolite was estimated by Bailey et al. to be $11 \%$ in pregnant women and up to $25 \%$ in infants $[9,13]$. The "gold standard" for adequate separation of 3-epimers and $24,25(\mathrm{OH}) \mathrm{D}$ metabolites, which is the function of LC-MS/MS, cannot be commonly implemented because of economical and organisational reasons. That is why methods used for vitamin $D$ analysis should be standardised with comparable reference material. The National Institutes of Standard and Technology has developed standardised Calibration Solutions - NIST SRM 2972 (which include both forms: $25(\mathrm{OH}) \mathrm{D}_{2}$ and $\left.25(\mathrm{OH}) \mathrm{D}_{3}\right)$, which allows standardisation of different available methods used for the measurement of $25(\mathrm{OH})$ $\mathrm{D}$ and also allows harmonisation of results of vitamin $\mathrm{D}$ concentration obtained from different laboratories [14].

The growing need for $25(\mathrm{OH}) \mathrm{D}$ testing forced most of the laboratories to implement fast and accurate tests for routine evaluation of vitamin D status. The Federal Drug Administration from early the 2000s approved the first fully automated immunoassay method for $25(\mathrm{OH})$ $D$ measurement [11]. Lately a new homogenous assay measuring $25(\mathrm{OH}) \mathrm{D}$ was adapted on general chemistry analysers. This new approach is based on the principle of $\alpha$-complementation of the $\beta$-galactosidase enzyme and reaction of the competition between an enzyme donor-25(OH)D conjugate, an anti-vitamin D antibody 
and the 25(OH)D in the blood [11]. This method was fully validated for the use on several chemistry analysers [11]. Our study aimed to assess the performance of two different methods, one available on an immunoassay automated system and the other on a general chemistry system, for measurement of $25(\mathrm{OH}) \mathrm{D}$ in children. We compared IDS-iSYS 25-hydroxy vitamin $D^{S}$ assay performed on an IDS-iSYS (Immunodiagnostic Systems) and Diazyme 25(OH)D assay (Pointe Scientific) performed on a Pentra 400 general chemistry analyser (Horiba). Comparison was performed on 100 serum samples collected from school-children.

\section{Subjects and materials}

One hundred presumably healthy children aged 9-11 years ( 45 boys and 55 girls) were included in the study. Blood samples were taken in the fasting state. Anthropometric measurements (height and weight) were conducted and body mass index percentiles were calculated with an online BMI calculator (based on the "OLAF" project). The BMI percentiles classification was accepted according to the International Obesity Task Force (IOTF); optimal weight: $\mathrm{BMI} \geq 5$ and $<85$ percentile; overweight: $\mathrm{BMI} \geq 85$ and < 95; obesity: $\mathrm{BMI} \geq 95$ percentile. Subjects were divided based on BMI percentiles into two groups: with optimal weight $(\mathrm{N}=50)$ and with overweight and obesity $(\mathrm{N}=50)$.

This study was approved by the Bioethics Committee of the Collegium Medicum in Bydgoszcz and Nicolaus Copernicus University in Toruń.

\section{Methods}

\section{IDS-iSYS 25(OH)DS assay (Immunodiagnostic Systems Ltd, Boldon, United Kingdom).}

This assay of the quantitative determination of 25-hydroxyvitamin D [(25(OH)D] and other hydroxylated metabolites in human serum was performed on an IDS-iSYS automated analyser. The method used in this assay is based on immunochemiluminescence technology (CLIA) and is aligned to NIST SRM 2972. The assay is traceable to the isotope dilution-liquid chromatography/tandem mass spectrometry (ID-LCMS/MS). Cross-reactivity with 3-epi-25(OH)D2 and with 3-epi$25(\mathrm{OH}) \mathrm{D} 3$ is $1 \%$ at $25(\mathrm{OH}) \mathrm{D}$ concentration $100 \mathrm{ng} / \mathrm{mL}$ (according to manufacturer's insert).

\section{5-hydroxy vitamin D assay (Pointe Scientific)}

Assay for quantitative determination of $25(\mathrm{OH}) \mathrm{D}$ by Pointe Scientific was performed on a clinical chemistry analyser - Pentra 400 (Horiba). The principle of the assay is based on $\alpha$-complementation of the $\beta$-galactosidase and competition between enzyme donor$25-(\mathrm{OH}) \mathrm{D}$ conjugate, antibody of vitamin $\mathrm{D}$, and the 25(OH)D in the serum sample (EIA). The concentration of vitamin $D$ in serum is proportional to the activity of $\beta$-galactosidase with maximum absorbance at $415 \mathrm{~nm}$ [11]. Cross-reactivity with 3-epi-25(OH)D2 is $55.1 \%$ and with 3 -epi-25(OH)D3 is $66.7 \%$ at $25(\mathrm{OH}) \mathrm{D}$ concentration $4 \mathrm{ng} / \mathrm{mL}$ (according to manufacturer's insert).

\section{Statistical analysis}

Results of this study were analysed with Bland-Altman regression. Correlations were assessed by Spearman's coefficient (rho) and concordance correlation coefficient (CCC). Basic statistics were performed by using the D'Agostino-Pearson test. For considering statistical significance a $p$ value was established at the level of $<0.05$. MedCalc Statistical Software trial version 16.2.1 (MedCalc Software BVBA, Ostend, Belgium; https://www.medcalc.org; 2016) was used for statistical analysis.

\section{Results}

Subjects taking part in this study were divided into two groups: children with optimal weight $(\mathrm{N}=50)$ and children with overweight/obesity $(N=50)$. The average $\mathrm{BMI}$ percentile in a subgroup with optimal weigh was 45 , and with overweight/obesity it was 93 . Mean serum 25(OH)D concentration measured by EIA in all children was significantly higher than with CLIA, $28.06 \mathrm{ng} / \mathrm{mL}$; $95 \% \mathrm{Cl}(25.37$ to 30.75$)$ vs. $21.13 \mathrm{ng} / \mathrm{mL} ; 95 \% \mathrm{Cl}(20.15$ to 22.11) $(p<0,0001)$. Comparison of vitamin D concentrations distribution performed on Pentra 400 and IDS-iSYS systems are shown in Figure $1 \mathrm{~A}-\mathrm{B}$. The average serum $25(\mathrm{OH}) \mathrm{D}$ concentrations in the subgroup of children with optimal weight was significantly higher with EIA (32.93 ng/ml; 95\%Cl [28.85 to 37.00]) than with CLIA (21.50 ng/mL; 95\%Cl [22.03 to 22.98]) ( $p<0.0001)$, whereas in the subgroup with overweight/obesity both means were similar $(23.20 \mathrm{ng} / \mathrm{ml}$ [20.11-26.29] and $20.76 \mathrm{ng} / \mathrm{ml}$ [19.42-22.09]); $\mathrm{p}=0.15$.

Method comparison requires that specimens are assayed by both methods and the results are compared to assess the bias that is used to express the closeness of agreement between the average value obtained from a series of measurements and the true value [15]. Estimation of mean bias was performed after Bland-Altman plots were calculated (Figure $2 \mathrm{~A}-\mathrm{C}$ ). The highest mean bias for enzymatic method (EIA) was identified for the subgroup of children with optimal weight, and equalled 35.3. In children with overweight/obesity the mean bias for the EIA method was the lowest, and equalled 


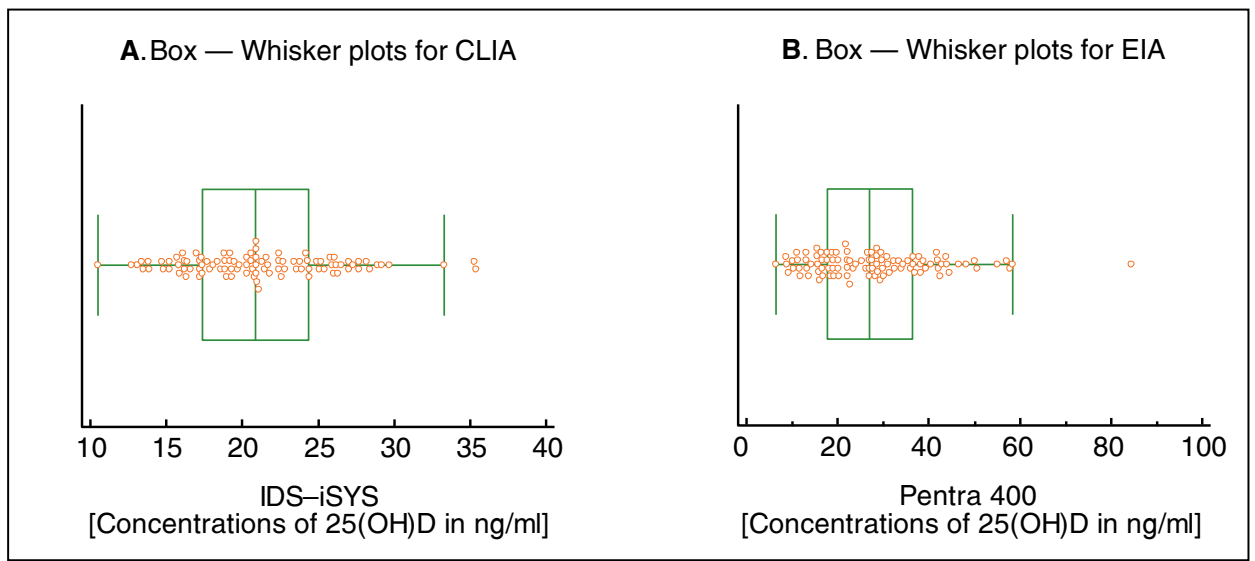

Figure 1 A-B. Distribution of $25(\mathrm{OH}) \mathrm{D}$ concentrations measured in the whole group of children by using two different methods.

2.0. Measurements by enzymatic method in the whole group showed a positive mean bias of 18.7 .

Next, a nonparametric Spearman's coefficient of rank correlation (rho) was calculated for all participants and two subgroups. Spearman's correlation for all subjects showed rho $=0.47$ with $95 \% \mathrm{Cl}(0.30$ to 0.61$)$ and significance level $p<0.0001$, which indicated "moderate correlation". The concentration of 25(OH)D in $(\mathrm{N}=50)$ when comparing two methods characterised with Spearman's rho was 0.38 with $95 \% \mathrm{Cl}(0.11$ to 0.60 ) in children with optimal mass, indicating "weak correlation" [16]. Positive correlation on "moderate level" was found in a subgroup of overweight/obese children (rho $=0.59$ with $95 \% \mathrm{Cl}[0.37$ to 0.75$]$ ).

Concordance correlation between the two methods was evaluated, and the concordance correlation coefficient was calculated for assessment of the strength of the agreement. The concordance correlation coefficient $r_{\mathrm{c}}$ contains a measurement of precision $\rho$ and accuracy $\mathrm{C}_{\mathrm{b}}$.

Concordance for all paediatric samples was poor: $p_{c}=0.26$ with $95 \% \mathrm{Cl}(0.17$ to 0.35$) ; p_{c}=p(0.50)$ $\mathrm{xC}_{\mathrm{b}}(0.52)$. For samples of children with optimal body mass the concordance coefficient was even lower $p_{c=}$ 0.18 with $95 \% \mathrm{Cl}(0.06$ to 0.29$) ; \mathrm{p}_{\mathrm{c}}=\mathrm{p}(0.43) \times \mathrm{C}_{\mathrm{b}}(0.41)$. Poor concordance between two methods was also found in a subgroup with overweight and obesity: pc was only 0.44 with $95 \% \mathrm{Cl}(0.29$ to 0.57$) ; p_{c}=p(0.63)$ $\mathrm{xC}_{\mathrm{b}}(0.70)$ (Figure $3 \mathrm{~A}-\mathrm{C}$ ).

\section{Discussion}

Requests for vitamin D measurements have escalated immensely during the past 10 years. Such a big workload of requested tests has forced clinical laboratories to replace highly specific but simultaneously expensive and demanding methods such as HPLC or LC-MS/MS with fully automated techniques adapted on routine analysers. Although direct methods like isotope dilution LC-MS/MS are still considered as the "gold standard" for evaluation of 25(OH)D concentration, a wide variety of assays launched on automated analysers has become an available alternative for routine vitamin D assessment [17-18]. The new automated assays for vitamin $D$, which have recently emerged on the in vitro diagnostic market, are burdened with unsatisfactory analytical accuracy and precision as well as a lack of standardisation [19]. Analytical difficulties result from the use of unspecific antibodies against $25(\mathrm{OH}) \mathrm{D}$, interference of different vitamin $D$ metabolites in the assay, and ineffective separation of 25(OH)D from VDBP [20].

We evaluated the performance of two different routine methods for $25(\mathrm{OH}) \mathrm{D}$ quantification in a set of paediatric samples. The newly developed enzyme-immunosorbent method performed on a general chemistry analyser was compared to the recalibrated IDS-iSYS $25(\mathrm{OH}) \mathrm{D}^{\mathrm{s}}$ immunochemiluminescence method. The mean concentration of 25(OH)D assayed with EIA method was significantly higher than the one measured with CLIA. With the use of EIA for 25(OH)D measurement, $33 \%$ of all tested paediatric samples were identified as vitamin $D$ deficient $(<20 \mathrm{ng} / \mathrm{ml}$ ) whereas with the use of CLIA $43 \%$ of samples were identified as vitamin D deficient. Differences in the assessment of the $25(\mathrm{OH})$ $D$ status with the use of these two methods may result from the cross-reactivity reactions of antibodies used with C3-epimers present in the serum. Because of the high percentage (51-62\%) of cross-reactivity with 3-epi-25-hydroxyvitamin D, the enzymatic method seems to be unsuitable for measurements of vitamin $D$ in paediatric samples [11]. A recent study by Stepman et al. showed that 3-epi metabolites could be identified not only in children but also in adults, reaching up to 


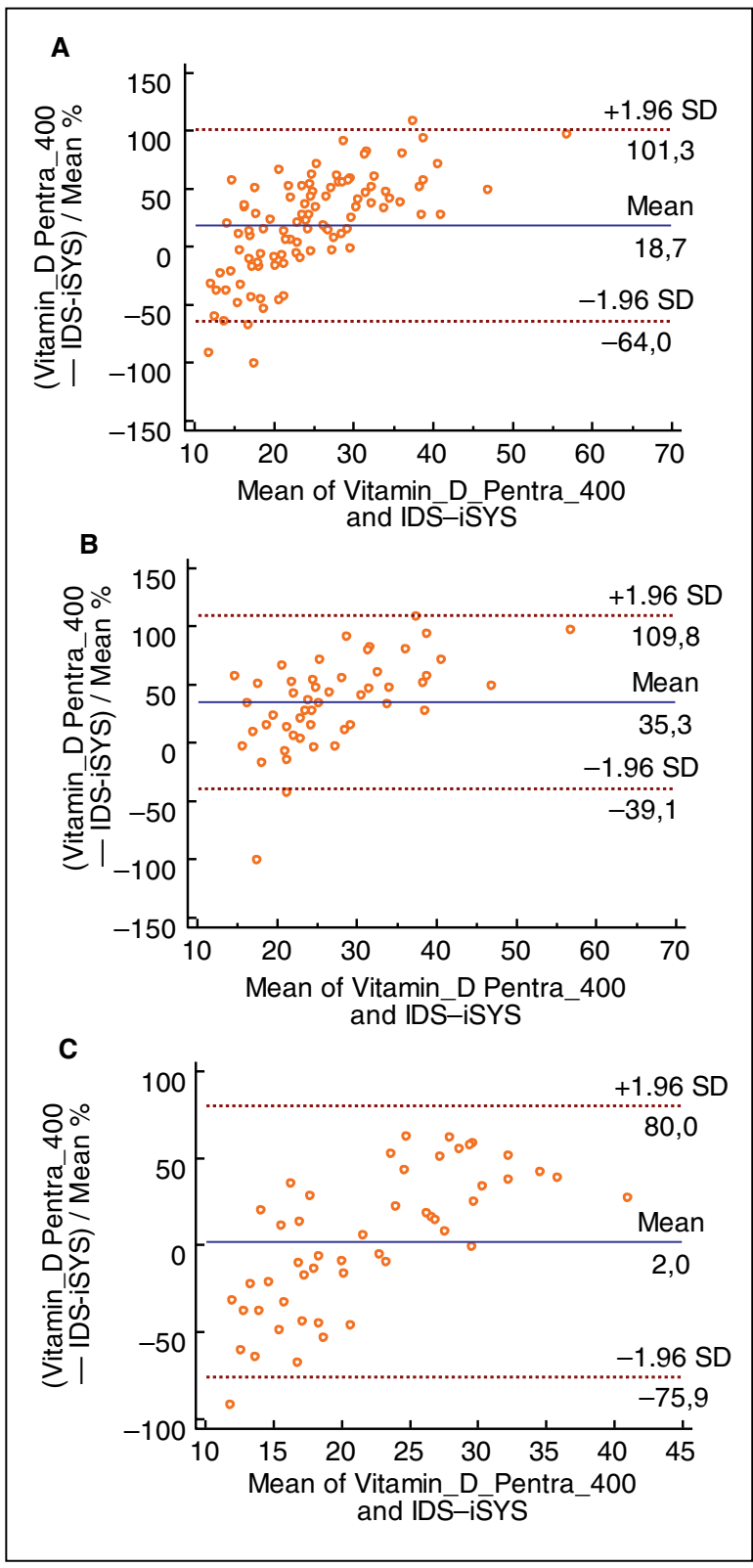

Figure 2 A-C. Bland-Altman plots illustrated bias in the whole group of participants $(A)$, subgroup with optimal weight $(B)$ and overweight/obesity $(C)$.

$17 \%$ of total $25(\mathrm{OH}) \mathrm{D}[13,17]$. Evaluation of mean bias was achieved by Bland-Altman calculations. According to the Endocrine Society suggestion, the maximum acceptable performance goals for mean bias of assays measuring $25(\mathrm{OH}) \mathrm{D}$ is $15.8 \%$ [21]. In our study the mean bias for enzymatic compared to CLIA method in all paediatric samples was 18.7. In samples from overweight/obese children the mean bias was only $2.0 \%$ (LoA: $80 \%$ to $-75.9 \%$ ), which could result from the lower arithmetic mean of 25(OH)D concentration in this set of samples. For the purpose of our study we used
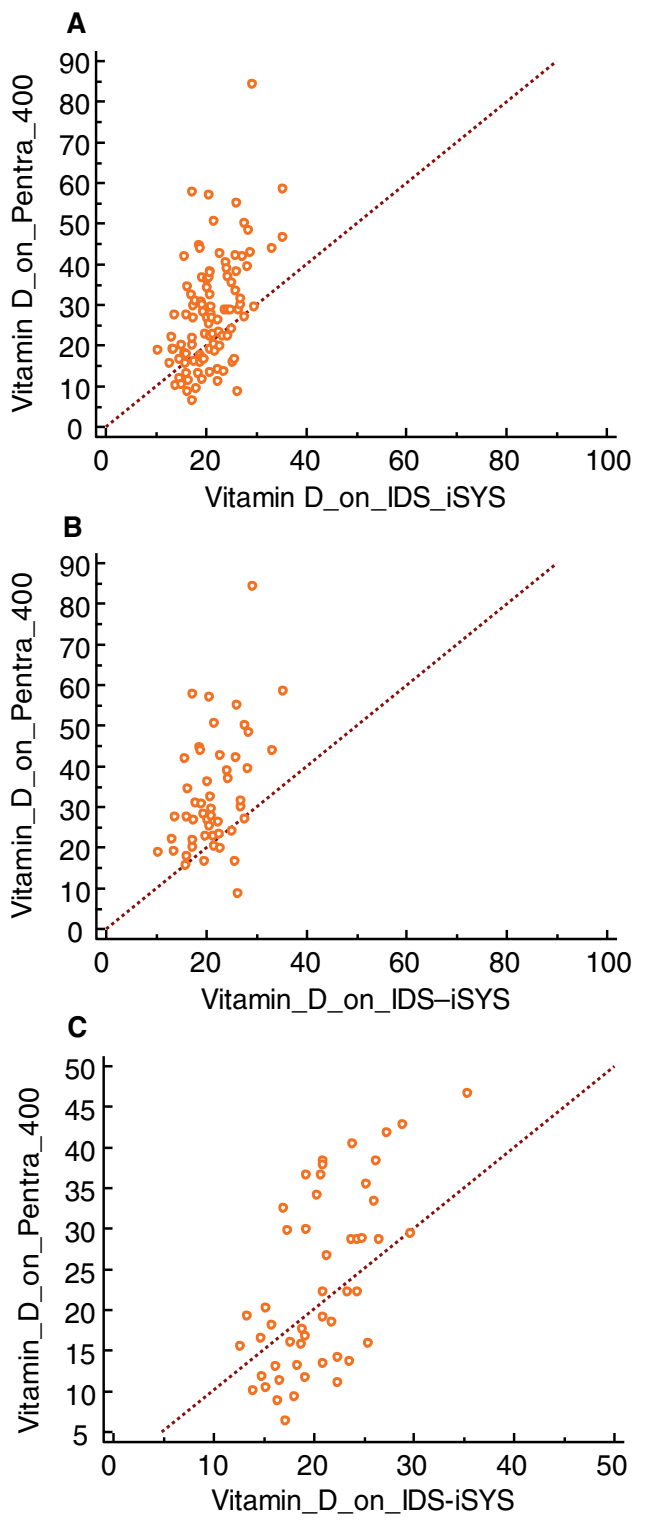

Figure 3 A-C. Scatter diagrams for concordance correlation coefficient (CCC). A- the whole group, B- subgroup with optimum weight, C- subgroup with overweight/obesity

two statistical parameters for comparisons between enzymatic and CLIA methods, which were: Spearman's and concordance correlation. The Spearman's rank correlation has shown positive "moderate correlation" (rho=0.47) between EIA and CLIA. Differences in correlation were identified in a set of samples from children with optimal mass $(\mathrm{rho}=0.38)$ and overweight/obesity (rho $=0.59$ ) with stronger positive correlation but on the "moderate" level in children with BMI $\geq 85$ percentile. According to McBride descriptive scale the strength of agreement between enzymatic and CLIA methods 
indicated a "poor correlation" $\left(p_{c}=0.26\right)$ [16]. Slightly better concordance correlation was observed in overweight/obese children $\left(p_{c}=0.44\right)$ but still an even "moderate" level of coefficient correlation was not achieved. Based on correlation factors calculated for $25(\mathrm{OH}) \mathrm{D}$ concentrations for enzymatic and CLIA methods, it is not possible to recommend the use of these techniques interchangeably for routine diagnostic purposes. The evaluated EIA method for 25(OH)D measurement in paediatric samples showed excessive mean bias and also unacceptable concordance correlation. Blood samples used in this study were taken from children aged 9-11 years, and we assume that the differences between $25(\mathrm{OH}) \mathrm{D}$ values obtained with the use of two chosen methods are due to cross-reactivity with 3-epimers.

\section{Conclusions}

The two compared technologies for $25(\mathrm{OH}) \mathrm{D}$ measurement, enzyme-immunosorbent and immunochemiluminescent, showed moderate correlation and poor concordance. The proper selection of assay for accurate assessment of vitamin D status in paediatric samples is necessary to avoid misdiagnosis.

\section{References}

1. Dusilová-Sulková S. Vitamin D metabolism and vitamin D traditional and nontraditional, target organs: implications for kidney patients. J Ren Care. 2009; 35 Suppl 1: 39-44, doi: 10.1111/j.1755-6686.2009.00066.x, indexed in Pubmed: 19222730.

2. Pludowski $P$, Grant W, Bhattoa $H$, et al. Vitamin D Status in Centra Europe. International Journal of Endocrinology. 2014; 2014: 1-12 doi: 10.1155/2014/589587

3. Torun E, Gönüllü E, Ozgen IT, et al. Vitamin d deficiency and insufficiency in obese children and adolescents and its relationship with insulin resistance. Int J Endocrinol. 2013; 2013: 631845, doi 10.1155/2013/631845, indexed in Pubmed: 23606841.

4. Olson ML, Maalouf NM, Oden JD, et al. Vitamin D deficiency in obese children and its relationship to glucose homeostasis. J Clin Endocrinol Metab. 2012; 97(1): 279-285, doi: 10.1210/jc.2011-1507, indexed in Pubmed: 22072738.
5. Peterson C. Vitamin D deficiency and childhood obesity: interactions, implications, and recommendations. Nutrition and Dietary Supplements. 2015: 29, doi: 10.2147/nds.s52024.

6. Bartoszewicz Z, Kondracka A, Bednarczuk T. Wysoka trwałość 25-hydroksy-witaminy D w próbkach surowicy przetrzymywanych w różnych warunkach podczas rutynowo wykonywanych pomiarów immunochemicznych. Diagn Lab. 2012; 48: 299-302.

7. Szternel $Ł$. Odrowąż-Sypniewska G. Witamina D - standaryzacja oraz efekt terapeutyczny. Beckman Coulter Bliżej Ciebie. 2014; 1: 3-6.

8. Kołłątaj W, Kołtątaj B, Klatka M, et al. Vitamin D - recommendations or the need for individualization of dosage? Pediatric Endocrinology. 2015; 14(1): 11-21, doi: 10.18544/ep-01.14.01.1506.

9. Odrowąż-Sypniewska G, Siódmiak J, Mańkowska-Cyl A. Comarision of two immunoassays for vitamin D measurement — is age a confounder? Standardy Med Pediatr. 2015; 12: 817-821.

10. Engelman $C D, B o R, Z u e l s d o r f f M$, et al. Epidemiologic study of the $C-3$ epimer of 25-hydroxyvitamin D(3) in a population-based sample. Clin Nutr. 2014; 33(3): 421-425, doi: 10.1016/j.clnu.2013.06.005, indexed in Pubmed: 23831447

11. Saida FB, Chen X, Tran K, et al. First 25-hydroxyvitamin D assay for general chemistry analyzers. Expert Rev Mol Diagn. 2015; 15(3): 313-323, doi: 10.1586/14737159.2015.988144, indexed in Pubmed: 25434745.

12. Hsu SA, Soldo J, Gupta M. Evaluation of two automated immunoassays for 25-OH vitamin D: comparison against LC-MS/MS. J Steroid Biochem Mol Biol. 2013; 136: 139-145, doi: 10.1016/j.jsbmb.2012.11.005, indexed in Pubmed: 23202147

13. Enko D, Kriegshäuser G, Stolba R, et al. Method evaluation study of a new generation of vitamin D assays. Biochem Med (Zagreb). 2015; 25(2): 203-212, doi: 10.11613/BM.2015.020, indexed in Pubmed: 26110032.

14. Montgomery R. Standard Reference Materials; National Institute of Standards and Technology (Spotlight), 2010. https://www-s.nist. gov/srmors/certArchive.cfm.

15. Johnson R. Assessment of ias with Emphasis on Method Comparison Clin Biochem Rev, 2008; 29: 37-42. https://www.ncbi.nlm.nih. gov/pmc/articles/PMC2556581/.

16. McBride GA. proposal for strength-of-agreement criteria for Lin's Concordance Correlation Coefficient. NIWA Client Report. ; 2015: 1-14.

17. Farrell CJL, Martin S, McWhinney B, et al. State-of-the-art vitamin D assays: a comparison of automated immunoassays with liquid chromatography-tandem mass spectrometry methods. Clin Chem. 2012; 58(3): 531-542, doi: 10.1373/clinchem.2011.172155, indexed in Pubmed: 22230812.

18. Lippi G, Salvagno GL, Fortunato A, et al. Multicenter Comparison of Seven $25 \mathrm{OH}$ Vitamin D Automated Immunoassays. J Med Biochem. 2015; 34(3): 344-350, doi: 10.2478/jomb-2014-0054, indexed in Pubmed: 28356846.

19. Lensmeyer GL, Wiebe DA, Binkley N, et al. HPLC method for 25-hydroxyvitamin D measurement: comparison with contemporary assays. Clin Chem. 2006; 52(6): 1120-1126, doi: 10.1373/clinchem.2005.064956, indexed in Pubmed: 16574756

20. Herrmann M, Harwood T, Gaston-Parry $O$, et al. A new quantitative LC tandem mass spectrometry assay for serum 25-hydroxy vitamin D. Steroids. 2010; 75(13-14): 1106-1112, doi: 10.1016/j.steroids.2010.07.006, indexed in Pubmed: 20654641.

21. Holick MF, Binkley NC, Bischoff-Ferrari HA et al. Endocrine Society. Evaluation, treatment, and prevention of vitamin D deficiency: an Endocrine Society clinical practice guideline. J Clin Endocrinol Metab. 2011; 96(7): 1911-1930, doi: 10.1210/jc.2011-0385, indexed in Pubmed: 21646368. 